\title{
Effect of Egyptian Culture on the Design of Jewelry (Cultural Design Based on Ancient Egyptian Patterns)
}

\author{
Eman Ramadan ${ }^{1,2}$ and $\mathrm{YuWu}{ }^{1}$ \\ ${ }^{1}$ School of Art and Design, Wuhan University of Technology, Wuhan, China. \\ E-mail: eman.salah@fsed.bu.edu.eg \\ ${ }^{2}$ Department of art education, college of specific education, Benha university, Egypt. \\ ORCID: 0000-0002-1567-7386. E-mail/ yuwu1981@gmail.com.
}

\begin{abstract}
We are now living in an era in which modern media and advanced technology, including satellites, satellite channels, and the information network, are intensifying, all of which are working to dissolve cultural subjectivity and remove popular legacies to replace them with Western cultural values and behavior patterns. Hence, the Egyptian researcher sees the necessity of reviving contemporary inspired, where every civilization in history has its own culture and pattern which always reflects civilization and expresses their lives and beliefs. Herein, we will mention about the ancient Egyptian civilization, in northeastern Africa that dates from the 4th millennium BCE. It has many achievements, which preserved in its art and monuments. It holds a fascination that continues to grow as archaeological finds expose its secrets. This article focuses on ancient Egyptian culture through the patterns of their beliefs, and how did these patterns affect the designs of the jewelry, and how we can benefit from these patterns in the creation of innovative designs. Here, we focused on the Egyptian pattern because of its great importance in ancient Egypt. Besides, its distinctive shapes enable us to create new modern designs for this era.
\end{abstract}

Keywords: Patterns, Egyptian culture, Cultural product, Jewelry design.

\section{Introduction}

History tells us that each culture has its own patterns, and this is a complex of ideas, from which the culture draws its strength. These patterns are unrepeatable and unique, it is characterized by a remarkable spontaneity in the sense that it never can totally be explained from the psychological qualities of man, or from certain social factors. The pattern of a culture is always an independent part, in which the creative force of the spirit reveals itself. For that same reason we note that for every living culture certain degree of adaptability i.e. (Hu et al., 2020). The ability of reorientating itself according to changed circumstances. The crux of the Explanation of modern culture is that its pattern is so complicated that it is hardly possible to formulate it in a satisfactory way. Nevertheless, it cannot be doubted that modern culture possesses its own pattern. One gets so much the more convinced of this the longer one has been immersed in the study of the cultures of the past. History is in this respect an excellent teacher (Alcaide-Marzal et al., 2020). It introduces the scholar into a land where passion and interest play no part any longer and where the problems

This Open Access article is published under a Creative Commons Attribution Non-Commercial 4.0 International License (http://creativecommons.org/licenses/by-nc/4.0/), which permits non-commercial re-use, distribution, and reproduction in any medium, provided the original work is properly cited. For citation use the DOI. For commercial re-use, please contact editor@rupkatha.com. 
and the relations can be considered in the light of pure truth. From the past one learns to understand the present, often by the marked contrast between the present situation and that of bygone days. This holds especially true when one recedes to a cultural spherein the far past, as, for example, the ancient Egyptian, which differs totally from the culture of the twentieth century (Al-Azmeh, 2015).

This consideration prompted the choice of the subject of this paper. It is dedicated to an analysis of the pattern of the ancient Egyptian culture. In the human civilization that has existed for thousands of years, there are a lot of cultures. Today, most of these cultures have disappeared whose brilliance has to be felt by exploring mysterious. Egypt is one of the four great birthplaces of human civilization. At a very early stage, ancient Egyptian civilization was highly developed, with an eternal role in the history of humans, (Gunn \& Muller, 1920). The field of industrial design has played an important role in embedding cultural elements into products and in increasing cultural value in the global competitive product market. Therefore, designing a product with local features in order to emphasize its cultural value has become a critical issue in the design process, further explore how to integrate the local cultural features into the product design, and try to build a conceptual framework of design transformation, this is a question worth studying (Moalosi et al., 2005).

The design is an important medium of communication, which is popularized in the culture of the earth to integrate the historical value with the modern life. In order to make some contributions to the inheritance of Egyptian cultural heritage and the economic value of cultural products, the traditional lotus flower pattern can be applied better to the cultural product design for modern life, (Baucom, 2006). Art in Egypt since ancient times where the earliest Egyptian art is very different from that of the pyramids and temples of the Pharaonic period. As well as differs from Islamic, Coptic, and folklore art, as each art appeared in a certain period of the history of Egypt, and each art has its distinctive features and the patterns on which it depended. The Pharaonic art in particular, represented a very important and great period in the history of Egypt, as it had a distinctive style and wonderful patterns (Shaobin, 2010), the article aims to transfer cultural features to design elements (product design oriented towards culture).

\subsection{Related work}

Design and culture have always been closely interrelated; however, in many instances, the design is flaunted as the accurate measurement of culture, rather than belonging to part of a cultural context of the society. The design has become the embodiment of a more extensive process of creative culture-mongering that has become a means to capture ideation, innovation, and enterprise and made to stand for cultural identity.

Apparently, for design, culture plays a vital role in value-adding and creates the core of product value. The same is true for culture, in which design is the vital force in enforcing cultural permaculture. Undeniably, culture as a form of creative resources can assist designers in catalyzing innovative product design. Some researchers described the history of the culture of Nanai shamanism and the object was the development of applied and decorative art handiworks through the culture of Far-Eastern indigenous people, such as of Nanai shamans (Gaidysheva and 
Parnyakov 2014).When learning the culture of far-eastern indigenous people, we have managed to bring Nanai culture elements into the design of new things (Of and Studies 2018). Olfat Shawky et al., studied the characteristics of the women's robes in some governorates from the Delta to Upper in Egypt. Each governorate has own characteristics (geography, weather, culture, customs, traditions, beliefs ...etc.) which reflect on clothes. Within the wrapping of king Tutankhamun's mummy, 143 pieces of jewelry were found; the importance of them is not only in the color of the metal or beads, but also in the originality of the design and motifs (Solar Beetle, Deities, Scarabs, Udjat Eye, Vulture, Falcon Wings, Carnelian Udjat, ...etc.). Egyptian woman's robes characteristics and Tutankhamun's jewelry motifs represent the challenge for designers to create women's fashion designs which emphasis on Egyptian identity. The researcher aims to create collections for women which are inspired from the characteristics of Egyptian women's robes in outlines and decorated with the motifs of Tutankhamun's jewelry. The research shows that the historical study is useful to create fashion designs, which combines originality and contemporary. Studying the characteristics of women's traditional robes and the motifs of Tutankhamun is a perfect way to create fashion designs for women, which reflect the Egyptian identity. The results revealed that the designs achieved the highest evaluation level were designs that coincided with the age group. Class of questionnaire in terms of compatibility with the customs and traditions, keeps up with fashion trends, emphasizes the character of Egyptian woman and her feminine look, succeeded in combine silhouettes of women traditional robes in Egypt and the aesthetics of Tutankhamun motifs. Tutankhamun motifs added aesthetic values to the design and it is suitable for women of the age group, (Mohamed and El-radi, 2019). Nagah Ashour developed strategic thinking in designing to achieve practical solutions for fashion designing. The researcher used the different silhouettes of traditional clothes from Siwa-Egypt as a source of inspiration to create fashionable designs for women. Models were drawn for the age group (25-40 years old). Models poses have been matched to the designs, which reveal the shape and style of the designs and enhance the dramatic effect desired by the designer. Ideas are sketched out in rough sketches. The sketches are then reworked and redrawn, starting with a quick pencil drawing and then being revised and redrawn into a full-color sketch (Ashour, Shaker, and Shaker 2019). El-Fishawy studied for the folklore in Menoufia Governorate represents one of the most important folk legacies that confirm our Egyptian identity, and this heritage represents its important and influential values in our national heritage as it is characterized by simplicity, innate nature, and preserving this popular heritage and reformulating. It in a way that is in line with contemporary reality is the problem of this research in the analysis of the most important features that characterized the popular costumes in Menoufia governorate from its distinctive elements and features. The possibility of designing multi-wear clothing supplements as a contemporary fashion inspired by the heritage clothes of the Monufia governorate and determining the opinions of specialists in the designs implemented and the extent to which they achieve the innovative aspect of the heritage clothing. The extent to which the functional aspect was achieved and to achieve the research objectives, the most important features that characterized the traditional clothing in the Menoufia governorate were analyzed from distinct elements and features. Five sets of multiple-wearing clothing supplements (accessories and shawls) were designed and implemented, inspired by the aesthetics of traditional clothing in the Menoufia governorate. 


\section{Overview about the Egyptian Patterns as a Model}

\subsection{The Egyptian patterns in Egyptian literature}

There were many Pharaonic symbols in the life of the ancient Egyptians and varied in their symbols, rituals and use, and a large number of them have reached the current society and are known by heart and mind, such as the "lotus flower", and others know it only in form, such as the "grandfather column", "Was scepter", and the Egyptian also excelled in making it and the symbol. To it and rely on it clearly in various aspects of his life and its fields, whether social, religious, cultural or recreational, and since these symbols had important meanings in the history of the pharaohs, it was necessary to address them, (Bruno, 2019). The ancient Egyptians made the famous key, and it is called the "Ankh" in Pharaonic form, mixing in its form the Pharaonic Egyptian form, and it often appears in the paintings of Egyptian tombs, and on the walls of museums and walls, and often appears in pictures that represent the resurrection of the deceased from the death of the deceased owner of the cemetery, and is called The "key to life"(McDonald, 2018). The ancient Egyptian often carried it alone, or with two other talismans, in a new symbol of strength and health as well. To a religious point of view, they also put metal models of the key of life on the graves after being polished with gold or copper and symbolizing the sun. The symbols of worship, resurrection, immortality and beliefs were not only for the pharaonic key, and he received a good fortune from the meanings and connotations of the ancient Egyptians (Efimova, 2017).

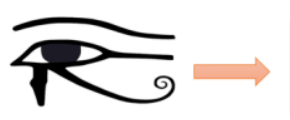

The Eye of Horus, also known as the Eye of Ra, was known in ancient Egypt as a slogan to protect against envy, disease, harmful animals and evil spirits and also good health, and royal power, it's the most famous of ancient Egyptian symbols $n$ the "Eye of Horus"

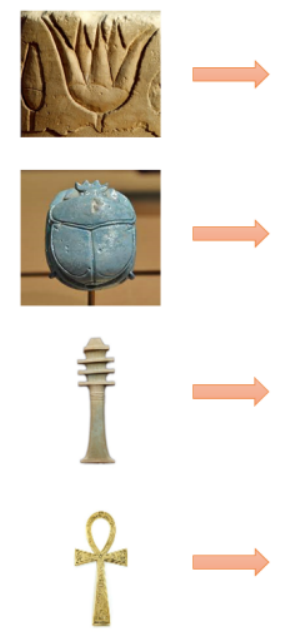

The lotus represents rebirth In ancient Egypt there were two main types of the lotus the white, and the blue also the lotus flower was used as a symbol for the unification of the two Egyptian kingdoms, Lotus was included in the manufacture of perfumes in ancient Egypt

The Egyptian Scarab Beetle was a symbol of death, rebirth, great power, guide and protect in the afterlife the scarab beetle was one of the most important and popular and amulets in for hundreds of years, worn by everyone living and the dead

The Djed is an ancient Egyptian symbol for stability Known as "The Backbone of Osiris This symbol was Osirian in nature and was primarily associated with themes of rebirth and regeneration.

The ankh is the most well-known symbol to come out of ancient Egypt the general meaning of the symbol In its hieroglyphic system of writing the ankh represents the concept of eternal life.

Figure 1. The most famous ancient Egyptian symbols.

\subsection{The art of jewelry in ancient Egypt}

The ancient Egyptian excelled in decorating with ornaments and jewelry, and their crafts were characterized by high technical accuracy and beauty of formation, and decorative elements were derived from nature such as the papyrus plant, palm, lotus flower, and precious stones. They used amulets that they believed would protect them from evil forces. The importance of jewelry for the 
Pharaohs is not limited to the acquisition of pure or precious and precious gold from materials and minerals but is represented in the originality and splendor of the designs. The symbols and drawings made of the most beautiful and accurate pure gold threads and wires inlaid with colored precious stones, the ingenuity and skill of the Egyptian goldsmiths (Cropley, 2016). Among the most famous archaeological evidence was the remains of the four bracelets that Petri found in Abydos and dating back to the era of the First Dynasty, and the golden plates and nails that adorned the wooden coffin found inside one of the catacombs of the Saqqara pyramid. The collection of antiquities of Queen "Hetep-Guards from the Fourth Dynasty, the golden falcon head that was found in the city of "Nekhen" from the Sixth Dynasty,(Society, 2016) and a group of antiquities of kings and princesses of the Middle Kingdom, the most important of which were "De Morgan" found in Lahun and Dahshur, and a group of monuments of King "Tutankhamun" and tomb ornaments. Tanis" and "Saptah" cemetery (Elhabashy \& Abdelgawad, 2019).

\subsection{The influence of ancient Egyptian art on jewelry design}

Azza Fahmy, an Egyptian jewelry designer and a pioneer in the world of jewelry design in the Arab world, has more than 30 years of experience in designing and manufacturing jewelry, ornaments and accessories, her designs are distinguished from others, as they are inspired by the ancient Egyptian civilization. She presented many collections inspired by various ages and civilizations, including the Mughals, Ottomans, Arabs, and many others (TBR's Creative and Cultural Team, 2015). Besides her collection contains bracelets, rings, necklaces, and necklaces. Azza Fahmy talks with gold and silver in a special language that simulates the time in which we live and at the same time makes us live in ancient times that we remember as soon as our eyes fall on its unique pieces. We also find that she imitates minerals and precious stones with secrets that only she can decipher. Her designs were not limited to keeping pace with fashion, but had a cultural goal. The designer describes her work saying: What I do is a revival of the ancient Egyptian heritage, and my message is to spread the heritage to all peoples because heritage is the Our identity, which is our beautiful inheritance, we must preserve it as much as possible.
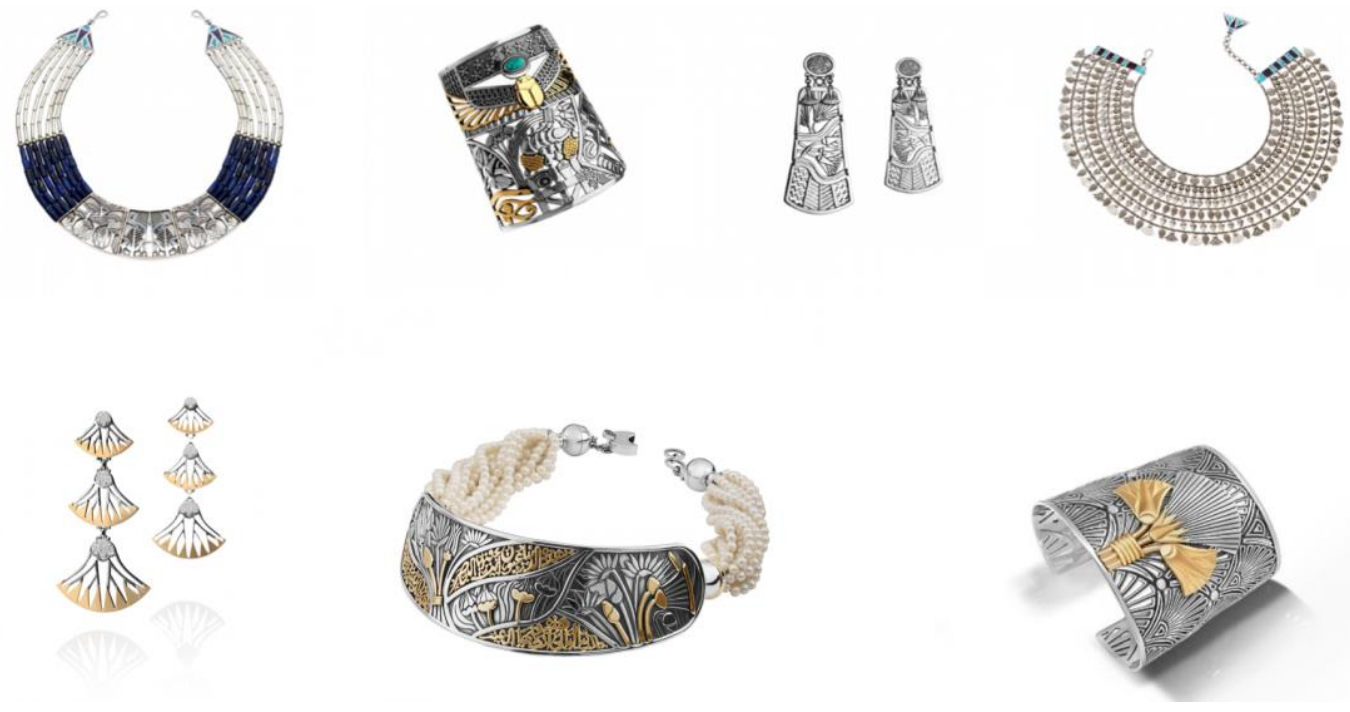

Figure 2: Some of the designs of jewelry inspired by Egyptian art (Azza Fahmy). 


\subsection{Design and Culture}

Early links between culture and design became apparent in the domain where civilization was evaluated through the evolution of objects and it was traced through the cultural characteristics left on those objects. Culture generates diversity and it is naturally revealed in all human action such as the products people design. The relationship between design and culture has taken many twists and turns throughout the last centuries, as design is seen both as a mirror and an agent of change. It is observed that modifications in the former's evolution both reflect and determine developments in the latter. Design changes culture and at the same time is shaped by it (Hu et al. 2020). For example, it is argued that cultural beliefs and social practices create and reinforce frames of meaning which determine ways of relating to a product. These cultural framings affect ways in which people use or do not use a particular product. It is culture that gives products meaning and provides the rituals within which artefacts are used and the values that are often reflected in their form and function. Cultural rights have been the focus of much debate since the decolonization movement following World War 2. Designers should focus on cultural rights. From a postcolonial perspective, the challenge is to develop ever-increasing respect for cultural rights in the world system in such a way that the world system itself evolves in accordance with cultures, (Moalosi, Popovic, and Hickling-Hudson 2010). The goal of cultural respect can be achieved by incorporating the historical and aesthetic values of users. This challenges designers to understand what and how cultural norms and values can be integrated in product design. It is underscored that designers need to recognize that people are cultural beings and the process of integrating cultural factors in their practice should be emphasized (Moalosi et al. 2005). Design is firmly embedded in user's culture: it does not take place in a cultural vacuum. Users are not just physical and biological beings, but socio-cultural beings. Baxter advances an argument that designers have not yet been able to consciously encode cultural phenomena to the same extent as physical and cognitive human factors due to inadequate research on the area. Each culture has evolved its own answers to its problems. The use of a society's cultural factors in design not only makes technologies more appropriate for their social context, but makes better use of culture itself as a resource for innovation. It is acknowledged that consideration of cultural factors may pave the way to the diversification of design concepts and facilitate product innovation (Design Council 2013). Furthermore, cultural issues should be integrated in the teaching of science and technology. Product design is an agent of change and it is important for designers to know how they can either undermine or support the indigenous cultural systems of the society. It is through artefacts that cultural values are communicated. Design is therefore, an important medium of communication (Baucom 2006), which expresses the values of the system within which it functions. In addition, users are not only competent members within their own cultures but they are also interpreters of their own and other cultures. Therefore, designers interpret and transform their needs and wants into product features that will give them narratives as well as benefits (Chai et al. 2018). Observes that the following criteria could be applied to assist designers in this transformation: (i) the interface and human interaction should support the user culture; (ii) the artefact form or shape should correspond to the culture and life cycle which conforms to the appropriate aesthetics; (iii) the artefact form or shape should convey humour or joy of that particular cultural set up; (iv)appropriate colours should be used to evoke desirable feelings within 
the same cultural context and; $(v)$ flexibility and adaptability of interaction should be related to culture.

\section{Methodology}

This research consists of two parts: primary data and secondary data. The primary data was conducted on the study of the lotus flower pattern and the analysis of this pattern with the expectation that it will be a framework for the design process. Secondary data is the conversion of this pattern into cultural product designs through jewelry design CAD software.

\subsection{Culture and Cultural Design Features}

Culture has been called "the way of life for an entire society, it generally refers to patterns of human activity and the symbolic structures that give such activity significance. Different definitions of "culture" reflect different theoretical bases for understanding, or criteria for evaluating, human activity. Based on linguistic, anthropological, and sociological studies (Hidayat et al., 2020), culture has been described as that which deals with the result of the evolutionary process in human civilization that involves language, customs, religion, arts, thought, and behavior. Some studies proposed a culture structure with multi-layers including 'artifact, value (Gilal et al., 2018), and basic assumptions which identified key design attributes including 'functional, aesthetic, and symbolic, developed a framework for studying cultural objects distinguished by three special levels: the outer (tangible) level, the mid (behavioral) level, and the inner (intangible) as shown in figure 3. Culture can be classified into three layers: (1) physical or material culture- including food, garments, and transportation related objects, (2) social or behavioral culture including human relationships and social organization, and (3) spiritual or ideal culture - including art and religion. These three culture layers can be fitted three culture levels given above, while cultural objects can be incorporated into cultural design. The three design features are identified as follows: (1) the inner level containing special content such as stories, emotion, and cultural features, (2) the midlevel containing function, operational concerns, usability, and safety, and (3) the outer level dealing with colors, texture, form, decoration, surface pattern, lines quality, and details (Lin et al., 2015).

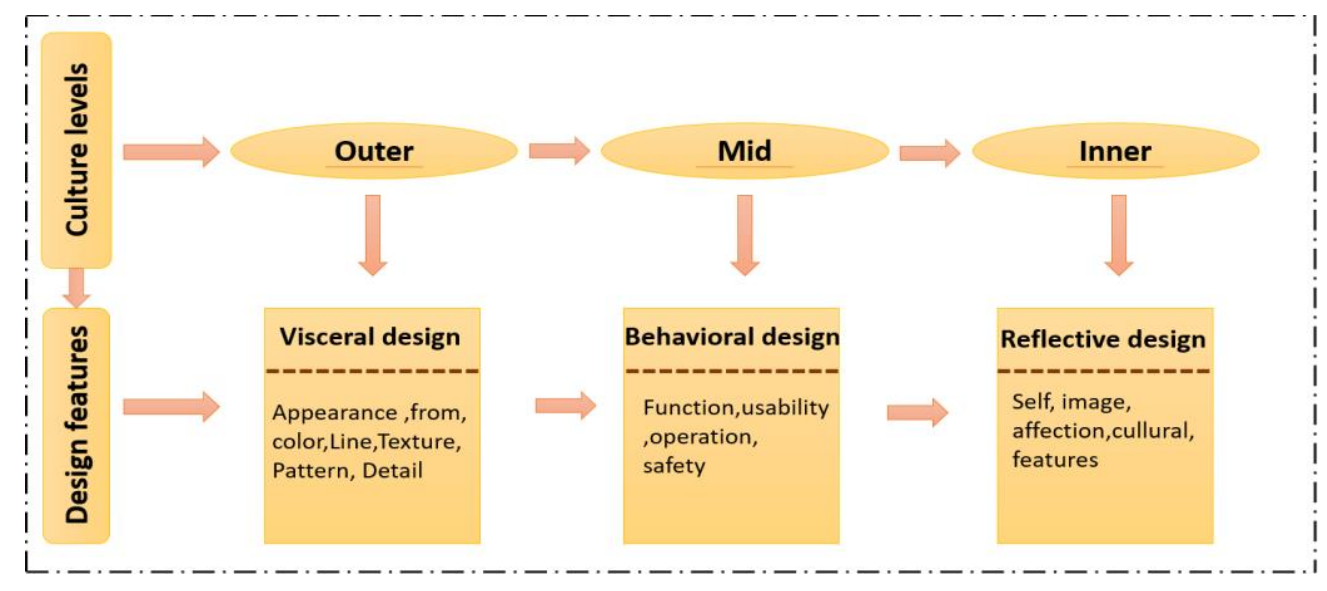

Figure 3. Three layers with design features. 


\subsection{Transformation process}

Based on the previous cultural levels and design feature the cultural feature transformation model consists of three main parts as shown in figure 4, including cultural features, design model, and cultural product. The conceptual model focuses on how to extract cultural features from cultural objects and then transfer these features to the design cultural products. The research method consists of three steps: Knowledge, transforming, and designing.

(a) Knowledge step: The cultural features were knowledge from native cultural objects including the outer level of colors, texture, pattern, and the mid-level of function.

(b) Transforming step: A transforming phase has translated the design information to design knowledge within a chosen cultural object and achieved some depth and experience of practice.

(c) Designing step: A designing phase possesses the design knowledge associated with the cultural features, the meaning of culture, an aesthetic sensibility, and the flexibility to adapt to various designs.

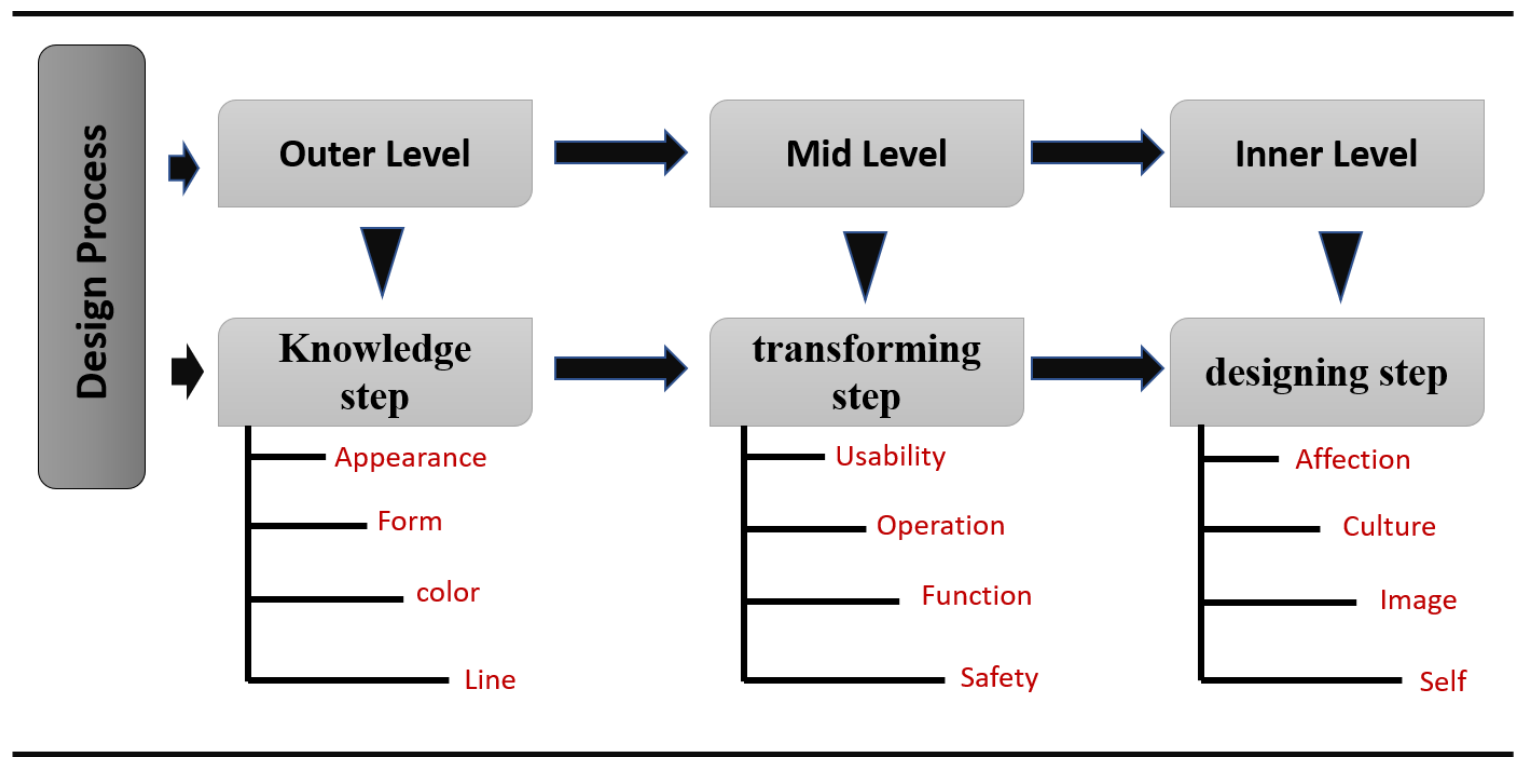

Figure 4. The cultural product design process consists of three main parts.

\section{Transform Egyptian Pattern into Jewelry Designs (Case Study).}

The application of cultural features is a powerful and meaningful approach to product a design. Consumers nowadays require a design that is not only functional and ergonomic but which also stimulates emotional pleasure. The results of studying the lotus pattern demonstrated that cultural features are a valuable element to embed into a product to emphasize its value or meaning, this conversion includes the three steps that we mentioned before as follows:

\subsection{Knowledge step}

This step used to find the key cultural features in the original cultural object. The scenario should take into consideration the overall environment in which the object is used the lotus pattern 
symbol was one of the symbols of high importance in the Egyptian civilization. Consequently, the ancient Egyptians relied on it for most of their lives, also painted and engraved it on their temples and tombs. Besides, the Egyptian kings wore jewelry and jewels that took the shape of the lotus pattern, since this symbol represents the new birth and the availability of wisdom and prosperity.

\subsection{Transforming step}

In this process, the designer brings some depth and experience in practice regarding design features. At the same time, it can relate this design knowledge to design problems and the designed form goals. As the transformation process is not dependent on the form only, the design includes the transfer of the cultural features of the lotus flower. In the form * of a modern design that fits more than one woman and carries the cultural features of the style, which helps to preserve the culture of each country.

\subsection{Designing step}

The third stage of design included converting designs into products using various programs that help the designer in converting the design into the closest product image, which is Auto Cad and Jewelry Cad. Once the lotus pattern is created in the design, the pattern is formed and divided into several different designs according to the previously mentioned design methods to create a variety of different designs that are part of ancient Egyptian art, upon completion of the implementation of the cultural product design model in the design process in the design of the most culture-oriented product, the lotus pattern explains the design process to convert cultural features into design elements. Where we implemented two jewelry designs inspired by the pattern of the Egyptian lotus flower bearing the cultural meaning, as the ancient Egyptians used the lotus flower pattern in making jewelry, as we mentioned before. We presented two designs that are able to compete in the global market and express the Pharaonic culture, and this would constitute a process of cultural exchange between countries.
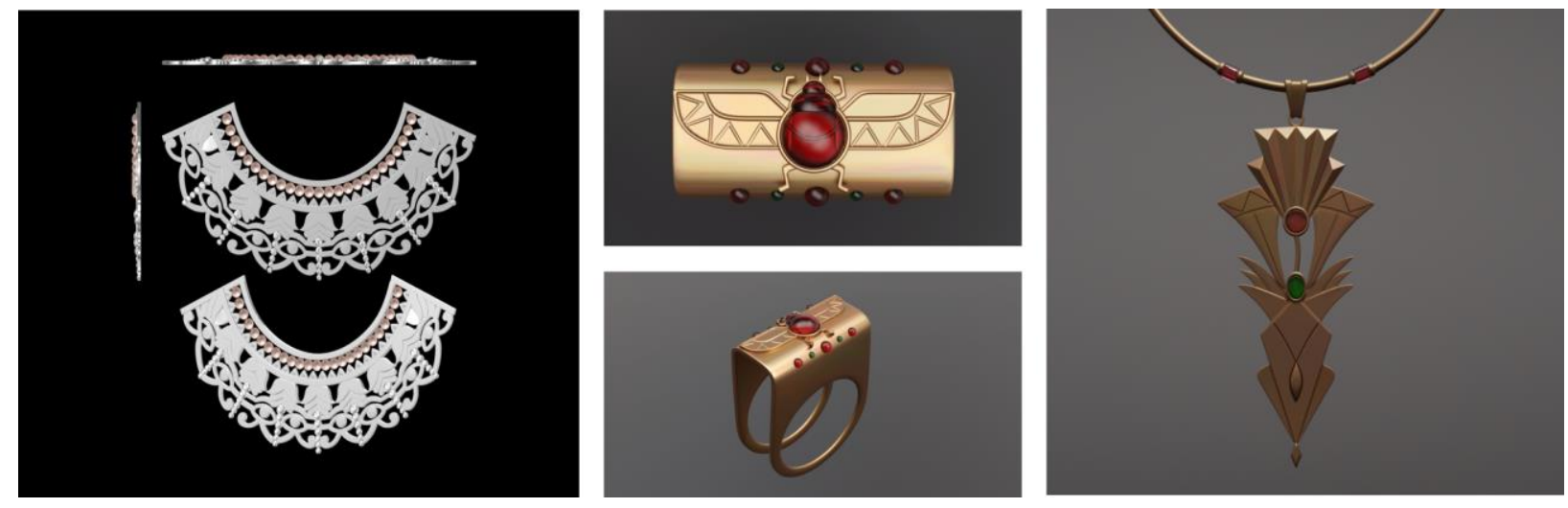

Figure 5. Some of the author's designs are inspired by ancient Egyptian patterns. 


\subsection{Design concept methods to transform Egyptian patterns into designs}

The evolution of a design pattern typically involves the addition or removal of a group of modeling elements. And this depends on the designer, his method of design, and the design that he uses. These methods differ from one designer to another because each designer has his own ideas and trends in design. Herein, we will mention the most important methods.

\subsubsection{Abstraction}

Abstraction in design is the process of removing successive levels of detail from a representation to capture only the essential features of a system. Through the process of abstraction, a designer can hide the irrelevant information about a system in order to reduce complexity and focus only on what is of essential interest. Abstraction within a design helps to define what is of general relevance to the whole system and what is specific to applications of it, thus making it possible to design multi-level systems where smaller, more specific subsystems are nested within larger more generic frameworks, (See figure 6).

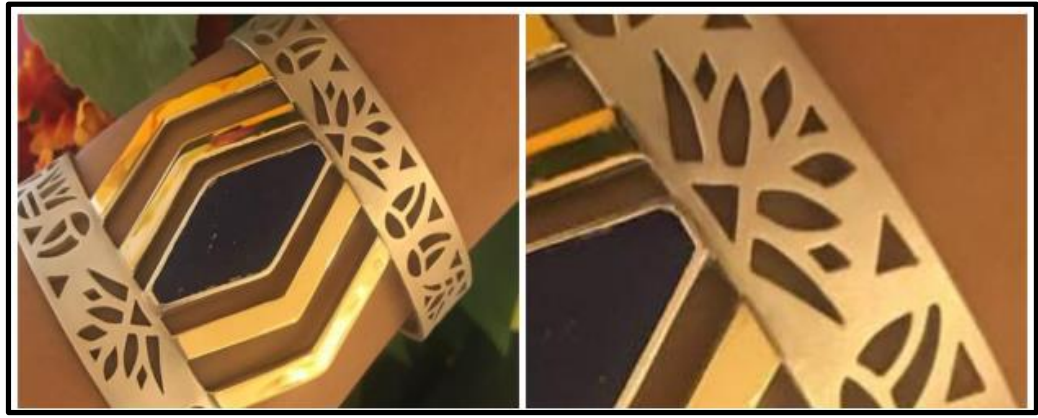

Figure 6. designs showing the abstraction of the Egyptian lotus flower.

Artwork analysis: In this design the designer used the abstraction method of lotus flower and turned it into a work of art. The designer abstracted the lotus flower in the form of geometric shapes taking the external form of the flower but without details, which gave the design a very simplified form of the lotus flower.

\subsubsection{Direct use}

It is through direct use of the design, i.e., we draw the design and implement the idea with the same basic form of the pattern without changing anything in it, we only design the shape as it is without removing or adding, (See figure 7).

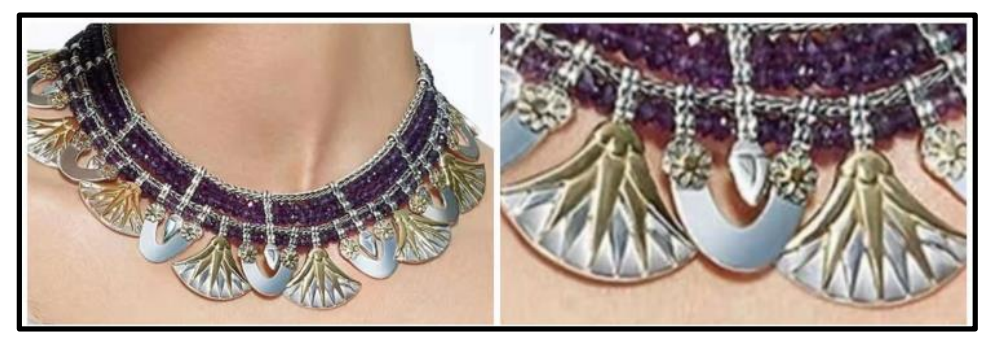

Figure 7. A picture showing the use of the basic shape of the lotus flower to transform it into a design. 
Artwork analysis: In this design the designer transformed the lotus flower into a work of art by using the basic shape of the lotus flower without alteration or modification in its main form, where the artwork shows the true shape of the lotus flower, which called (direct-use method).

\subsubsection{Repetition}

This step is done by repeating the model used in a specific way according to each designer, or by repeating a specific part of the model used in a way that suits the design and this repetition results in another and different design for the model used, (See figure 8).

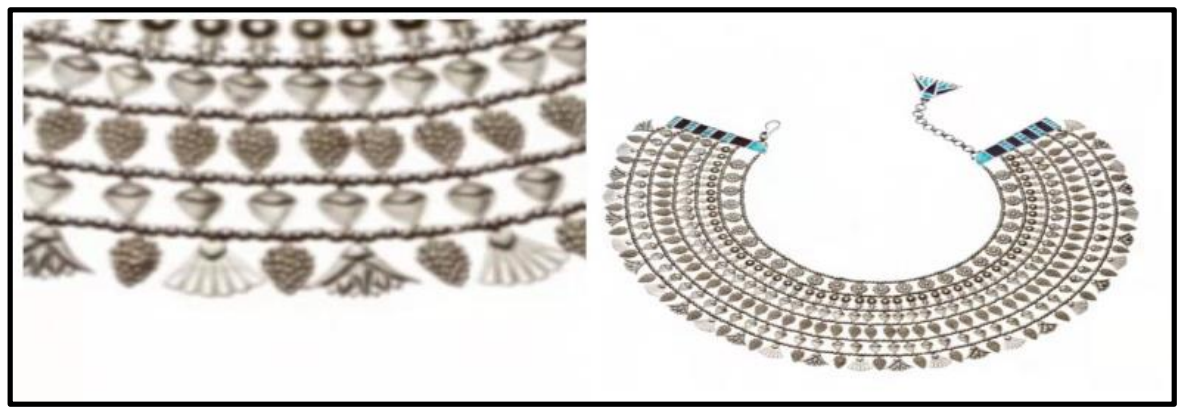

Figure 8. Picture showing use of the iterative method in a lotus flower pattern design.

Artwork analysis: In designing this section, the designer used the method of replication by repeating the shape of the lotus flower more than once in the artwork, adding some leaves to give a balance of design. Besides, giving the design a simple and attractive look.

\subsubsection{Overlap}

In this step, we make interventions between parts of the model or use other elements besides the model and make interventions between them and these interventions result in diversity between the elements where the parts of the model vary and become different and giving a different design, (See figure 9).
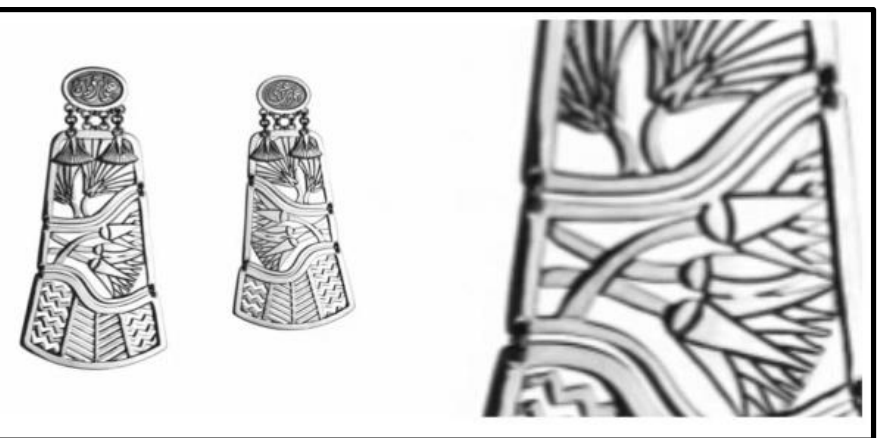

Figure 9. Image showing composition of lotus flower pattern by overlap.

Artwork analysis: The designer used the overlap method as he made interventions between three flowers in the middle of the artwork and two on the top in a simple way, resulting in a great design with some geometric shapes added below to give the design integration. 


\subsubsection{Delete and add}

In this step, one part of the form is deleted, and the other part is left to work on the design, or a new part is added to the form, which gives a different design. Deletion or addition is made based on the proportions of the model, and from this delete and addition a different design is produced, (See figure 10).

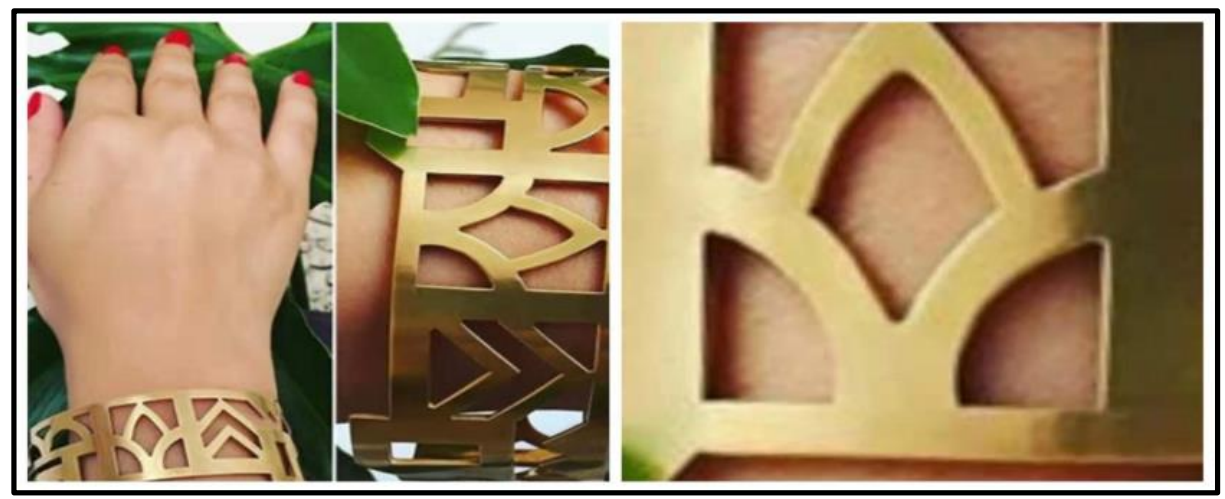

Figure 10. Image showing the use of the delete and add method in designing the lotus flower.

Artwork analysis: The designer here used the method of deletion and addition, as he deleted parts of the main shape of the lotus flower and showed the external form and structure of the lotus flower only, which gave the design a very simple shape.

\section{Conclusion}

In Pharaonic art, there are many patterns, and hieroglyphic writings. This study dealt with a detailed explanation of the Egyptian pattern in ancient Egyptian civilization and how it can be transformed into a design and some designs drawn from this pattern. In the future a different pattern can be used to invent new and modern designs of this style in many other areas of art such as fashion. Because these patterns benefit us in exchanging cultures and knowledge from other cultures, besides each civilization is full of many patterns that can be converted into modern designs fit for our time. The objective is the practice-based centered on a study to transform cultural features to design elements. In the process of applying cultural product design model in designing culture-oriented product, phrase 1 (Knowledge stage) is the stage of identifying potential cultural features was the most challenging start. It is a process involved a deep consideration of the feasibilities of the selected cultural features and its possibilities in transforming into design elements. Meanwhile, selected cultural features' contextual meaning and suitability for becoming a design product also required an analytical process. In the process of phase 2 (Translation stage) the interpretation of the cultural features into design elements required an analytical study of translating relevant features into the design. This stage is a high challenge for a designer, as translating cultural features into design elements is a process of generating new storytelling based on selected cultural features and turn it into relevant design elements for serving the design concept and aesthetic. In the process of phase 3 (Designing stage), design elements such as forms, colors, and composition required a repeatability of multiexperiment to finalize. 


\section{Funding Disclosure/Acknowledgement}

The authors gratefully acknowledge the Chinese Scholarships Council (CSC) Foundation (No. 2018Y90100034) for their financial support.

\section{References}

Al-Azmeh, A. (2015). Civilization, Concept and History of. In International Encyclopedia of the Social \& Behavioral Sciences: Second Edition (Second Edi, Vol. 3). Elsevier. https://doi.org/10.1016/B978-008-097086-8.62080-9

Ashour, Nagah, Rania Shaker, and Rania N. Shaker (2019). "Abstract:" 223-30.

Alcaide-Marzal, J., Diego-Mas, J. A., \& Acosta-Zazueta, G. (2020). A 3D shape generative method for aesthetic product design. Design Studies, 66, 144-176. https://doi.org/10.1016/j.destud.2019.11.003

Baucom, I. (2006). Cultural Studies. In Modern British and Irish Criticism and Theory: A Critical Guide.

Bruno, L. (2019). The Gods of The Egyptians. Journal of Chemical Information and Modeling, 53(9), 16891699. https://doi.org/10.1017/СBO9781107415324.004

Cropley, A. (2016). Ancient world conceptualizations of creativity. In The Curated Reference Collection in Neuroscience and Biobehavioral Psychology. Elsevier. https://doi.org/10.1016/B978-0-12-809324$5.23641-9$

Chai, Chunlei, Danni Shen, Defu Bao, and Lingyun Sun. 2018. "Cultural Product Design with the Doctrine of the Mean in Confucian Philosophy." Design Journal 6925:1-23

Design Council. 2013. "Design for Public Good." Annual Review of Policy Design 1(1):1-50.

Efimova, A. (2017). Masterpieces of Jeweller's Art in the Egyptian Style Made by Cartier in the Period of Art Deco. 103(Iccese), 16-17. https://doi.org/10.2991/iccese-17.2017.101

Elhabashy, S., \& Abdelgawad, E. M. (2019). The history of nursing profession in ancient Egyptian society. International Journal of Africa Nursing Sciences, 11, 100174. https://doi.org/10.1016/j.ijans.2019.100174

Gilal, F. G., Zhang, J., Gilal, N. G., \& Gilal, R. G. (2018). Integrating self-determined needs into the relationship among product design, willingness-to-pay a premium, and word-of-mouth: A crosscultural gender-specific study. Psychology Research and Behavior Management, 11, 227-241. https://doi.org/10.2147/PRBM.S161269

Gaidysheva, Maria, and Alexey V. Parnyakov. 2014. "Design of Applied and Decorative Art Elements Based on the Example of Nanai Shaman's Culture." Pacific Science Review 16(2):140-47

Gunn, B., \& Muller, W. M. (1920). Egyptian Mythology. In The Journal of Egyptian Archaeology (Vol. 6, Issue 1). https://doi.org/10.2307/3853723

Hidayat, J., Tjakra, G., Darmawan, R., \& Dharmawan, C. (2020). Hybrid Design Model in Cross Cultural Collaboration: Case Study - Contemporary Bamboo-Ceramic-Batik-Silver Crafts Made by Indonesian and Japanese Artists. Icmr 2018, 394-399. https://doi.org/10.5220/0008885703940399 
Hu, Yukun, Suihuai Yu, Yafang Ju, Dengkai Chen, Weiwei Wang, Yanpu Yang, and Chen Chen. 2020. Transforming Chinese Cultural Features into Modern Product Design. Vol. 12192 LNCS. Springer International Publishing

Hu, Y., Yu, S., Ju, Y., Chen, D., Wang, W., Yang, Y., \& Chen, C. (2020). Transforming Chinese Cultural Features into Modern Product Design. In Lecture Notes in Computer Science (including subseries Lecture Notes in Artificial Intelligence and Lecture Notes in Bioinformatics): Vol. 12192 LNCS. Springer International Publishing. https://doi.org/10.1007/978-3-030-49788-0_23

Lin, R., Kreifeldt, J., \& Hung, P. (2015). Cross-Cultural Design Applications in Mobile Interaction, Education, Health, Transport and Cultural Heritage. 9181, 263-273. https://doi.org/10.1007/978-3-31920934-0

Lin, Rungtai, Ricer Cheng, and Ming Xian Sun. 2007. "Digital Archive Database for Cultural Product Design." Lecture Notes in Computer Science (Including Subseries Lecture Notes in Artificial Intelligence and Lecture Notes in Bioinformatics) 4559 LNCS(PART 1):154-63.

Mohamed, Olfat Shawky, and Wafaa Abd Elradi. 2019. "Studying of Egyptian Woman's Robes Characteristics and Tutankhamun's Jewelry Motifs to Create Fashionable Designs." 4(1):265-79.

McDonald, J. A. (2018). Influences of egyptian lotus symbolism and ritualistic practices on sacral tree worship in the fertile crescent from 1500 BCE to 200 CE. Religions, 9(9), 3-7. https://doi.org/10.3390/rel9090256

Moalosi, R., Popovic, V., Hudson, A., \& Lall Kumar, K. (2005). Integration of culture within Botswana product design. International Design Congress.

Shaobin, L. (2010). Design elements in jewelry design. 2010 IEEE 11th International Conference on Computer-Aided Industrial Design and Conceptual Design, CAID and CD'2010, 1, 257-259. https://doi.org/10.1109/CAIDCD.2010.5681359

Society, A. P. (2016). Observations on Egyptian Ethnography, Derived from Anatomy, History, and the Monuments Author ( $\mathrm{s}$ ): Samuel George Morton Source : Transactions of the American Philosophical Society, Vol . 9, No . 1 ( 1846 ), pp . 93-159 Published by: American Philo. 9(1), 93-159.

Of, International Journal, and Fashion Studies. 2018. "Design of Multi-Wear Accessories Clothing as a Contemporary Fashion Inspired by the Traditional Clothing of Menoufia." 1(1):21-26.

TBR's Creative and Cultural Team. (2015). The role and value of design Working paper: Measuring and defining design. Economic Research \& Business Intelligence, August 22.

Eman Ramadan, received her bachelor's and master's degrees from Benha University, Egypt, Faculty of Specific Education, Art Education Department in 2013 and 2017, respectively. she is now a doctoral student at Wuhan University of Technology, College of Art and Design, China. Working as assistant lecturer at Benha University, Egypt. her major is jewelry design and interested in studying cultural product design.

Yu Wu, received his PhD. degree from Korea Advanced Institute of Science and Technology, Korea, in 2013. Since 2013, he has been a professor in the School of Art and Design at Wuhan University of Technology, Wuhan, China. His research interests are in industrial design, computational design, interaction design, and intelligent robot design. 